\title{
A prospective study of serum metabolites and glioma risk
}

\author{
Jiaqi Huang ${ }^{1}$, Stephanie J. Weinstein ${ }^{1}$, Cari M. Kitahara ${ }^{2}$, Edward D. Karoly ${ }^{3}$, Joshua \\ N. Sampson ${ }^{4}$ and Demetrius Albanes ${ }^{1}$ \\ ${ }^{1}$ Metabolic Epidemiology Branch, Division of Cancer Epidemiology and Genetics, National Cancer Institute, NIH, Department \\ of Health and Human Services, Bethesda, MD, USA \\ ${ }^{2}$ Radiation Epidemiology Branch, Division of Cancer Epidemiology and Genetics, National Cancer Institute, NIH, Department \\ of Health and Human Services, Bethesda, MD, USA \\ ${ }^{3}$ Director of Project Management, Metabolon, Inc., Morrisville, NC, USA \\ ${ }^{4}$ Biostatistics Branch, Division of Cancer Epidemiology and Genetics, National Cancer Institute, NIH, Department of Health \\ and Human Services, Bethesda, MD, USA
}

Correspondence to: Demetrius Albanes, email: DAA@NIH.GOV

Keywords: malignant glioma, metabolomics, prospective, arginine/proline metabolism, antioxidant

Received: April 23, $2017 \quad$ Accepted: June 29, $2017 \quad$ Published: July 31, 2017

Copyright: Huang et al. This is an open-access article distributed under the terms of the Creative Commons Attribution License 3.0 (CC BY 3.0), which permits unrestricted use, distribution, and reproduction in any medium, provided the original author and source are credited.

\section{ABSTRACT}

Malignant glioma is one of the most lethal adult cancers, yet its etiology remains largely unknown. We conducted a prospective serum metabolomic analysis of glioma based on 64 cases and 64 matched controls selected from Alpha-Tocopherol, BetaCarotene Cancer Prevention (ATBC) Study. Median time from collection of baseline fasting serum to diagnosis was nine years (inter-decile range 3-20 years). LC/MSMS identified 730 known metabolites, and conditional logistic regression models estimated odds ratios for one-standard deviation differences in log-metabolite signals. Forty-three metabolites were associated with glioma at $P<0.05$. 2-0xoarginine, cysteine, alpha-ketoglutarate, chenodeoxycholate and argininate yielded the strongest metabolite signals and were inversely related to overall glioma risk $(0.0065 \leq P<0.0083)$. Also, seven xanthine metabolites related to caffeine metabolism were higher in cases than in controls $(0.017 \leq P<0.042)$. Findings were mostly similar in high-grade glioma cases, although prominent inversely associated metabolites included the secondary bile acids glycocholenate sulfate and $3 \beta$-hydroxy-5-cholenoic acid, xenobiotic methyl 4-hydroxybenzoate sulfate, sex steroid 5alpha-pregnan3 beta, 20 beta-diol-monosulfate, and cofactor/vitamin oxalate $(0.0091 \leq P<0.021)$. A serum metabolomic profile of glioma identified years in advance of clinical diagnoses is characterized by altered signals in arginine/proline, antioxidant, and coffeerelated metabolites. The observed pattern provides new potential leads regarding the molecular basis relevant to etiologic or sub-clinical biomarkers for glioma.

\section{INTRODUCTION}

Brain cancer is one of the most fatal and devastating malignancies, given its poor prognosis and adverse impact on quality of life, including, particularly, cognitive function. Malignant glioma accounts for $80 \%$ of adult brain cancers [1], and its etiology remains largely unknown, with the exception of ionizing radiation and family history, and evidence pointing to inverse associations with asthma and allergies [1-7]. A spectrum of genetic alterations has been characterized for glioma, including germline and somatic mutations, recurrent translocations, and copy number variations, $[8,9]$ yet these do not account for all the underlying biology. Rapid development of technologies in liquid and gas chromatography, mass spectrometry and nuclear magnetic resonance have facilitated the 
measurement of a broad array of low molecular weight metabolites in biospecimens such as plasma and serum, urine and tissue. Quantification of the metabolome provides an integrated snapshot reflection of exogenous and endogenous exposures, and may thus help to identify novel disease associations and point to biochemical pathways involved in disease pathogenesis. Chinnaiyan and colleagues demonstrated unique tumor metabolomic signatures, involving cellular energy, anabolism and phospholipid pathways, that distinguished low-grade from high-grade gliomas and had prognostic relevance [10]. The significance of these metabolic differences to the etiology, early detection, and prevention of the disease remains to be established, however, including through prospective investigations $[11,12]$.

To address the potential role of altered metabolites and their related biological pathways in glioma tumorigenesis, we conducted a prospective case-control serologic analysis including 64 glioma cases nested within the Alpha-Tocopherol, Beta-Carotene Cancer Prevention (ATBC) Study cohort. According to the World Health Organization (WHO) grade for glioma (I-IV) [13], the present study includes 41 high-grade gliomas (grade IV), 19 lower-to-intermediate-grade gliomas (grades II and III; subsequently referred to "lower-grade"), and 4 cases of unknown grade [14].

\section{RESULTS}

Cases were similar to controls with respect to baseline characteristics, with the exception that they had lower average body mass index (BMI) $(P=0.025)$ and appeared to consume more coffee (although not statistically significantly different $(P=0.21)$ (Table 1$)$. The median time from serum collection to glioma diagnosis was nine years (inter-decile range $=3.0-20.0$ years). Based on the quality control samples, the median coefficient of variation (CV) across all the metabolites was $7 \%$ (interquartile range $=4 \%-14 \%$ ) and the median intraclass correlation coefficient (ICC) was 0.97 (interquartile range $=0.89-0.99$ ).

Serum metabolites related to risk of overall and high-grade glioma with a nominal $P$-value of $<0.05$ are listed in Tables 2 and 3, respectively, sorted by chemical class (also known as "super-pathway"), sub-class (also known as "sub-pathway") and $P$-values. No association reached significance after Bonferroni correction for multiple comparisons (threshold of $P=0.000068$ ). In the primary analysis of all cases and controls, we found that the amino acids 2-oxoarginine, cysteine and argininate, energy metabolite alpha-ketoglutarate, and lipid chenodeoxycholate yielded the strongest signals, being lower in cases than in controls $(0.0065 \leq \mathrm{P}<0.0083$, Table 2 ). Amino acid metabolites in the phenylalanine/tyrosine sub-pathway ( $\mathrm{N}$-acetyltyrosine, $\mathrm{N}$-acetylphenylalanine, phenyllactate and tyrosine; $0.011 \leq P<0.048$ ), and the tryptophan sub-pathway (N-acetylkynurenine, $\mathrm{N}$-acetyltryptophan and xanthurenate; $0.042 \leq P<0.045$ ) were also lower in cases. By contrast, the serum acylcarnitines stearoylcarnitine, margaroylcarnitine, and eicosenoylcarnitine $(0.016 \leq P<0.046)$, and xanthine (i.e., caffeine) metabolites 1-methylurate, 1-methylxanthine, paraxanthine, theobromine, 5-acetylamino-6-amino3-methyluracil, theophylline, and 7-methylxanthine $(0.017 \leq P<0.042)$ were higher in cases than in controls (Table 2), as were serum levels of 2-hydroxyglutarate (2$\mathrm{HG}$ ) (odds ratio $(\mathrm{OR})=1.53,95 \%$ confidence interval $(\mathrm{CI})$ : $0.98,2.39, P=0.06$; data not shown). Adjustment for age at baseline or diagnosis, BMI, history of diabetes, height, physical activity, cigarettes per day, or red meat or alcohol consumption did not alter the findings (data not shown).

High-grade glioma showed fewer but similar risk associations overall, although proportionally more metabolites were elevated in cases relative to controls (e.g., N-acetylglutamate, ribonate, and 5-methyluridine; $0.04 \leq P<0.02$; Table 3 ). Notably, xanthine compounds appeared unrelated to high-grade glioma. Prominent metabolite signals with inverse risk associations were the secondary bile acids glycocholenate sulfate and $3 \beta$-hydroxy-5-cholenoic acid, xenobiotic methyl 4-hydroxybenzoate sulfate, sex steroid 5alpha-pregnan3 beta, 20beta-diol monosulfate, and cofactor/vitamin oxalate (ethanedioate) $(0.0091 \leq P<0.021$; Table 3$)$.

Stratifying cases and their controls by median time from blood draw to diagnosis showed that several lysoplasmalogen, sphingolipid, and three of four benzoate metabolites were positively related to glioma within nine years of blood collection (Supplementary Table 1). By contrast, abundant diacylglycerol, monoacylglycerol, phospholipid, and sphingolipid metabolites were prominently and inversely related to cases that were diagnosed at least nine years after blood collection (Supplementary Table 2). We found that caffeine intake did not modify the association between identified caffeine related metabolites and glioma risk (Supplementary Table 3).

None of the top 10 principal components were significantly associated with glioma risk, with all tests showing $P \geq 0.034 \quad(P<0.005$ being the threshold). The Gene-Set Analysis (GSA) pathway analysis revealed primary bile acid, urea cycle/arginine and proline, tocopherol, and glycolysis/gluconeogenesis/pyruvate associations with overall glioma risk $(0.005 \leq P<0.048$; Table 4). Ascorbate and aldarate metabolites appeared to be related to high-grade glioma $(P=0.02)$, while glutamate, glycolysis/gluconeogenesis/pyruvate (i.e., cellular energy), eicosanoid and alanine/aspartate metabolites were related to lower-grade glioma ( $P=0.006,0.017,0.03$, 0.04 , respectively; Table 4$)$. The sub-pathway analysis stratified by time from blood collection to diagnosis revealed that primary bile acid metabolites were related to cases diagnosed within nine years of blood collection 
Table 1: Baseline characteristics of glioma cases and controls ${ }^{1}$

\begin{tabular}{|c|c|c|c|}
\hline & Controls & Cases & $P$-value ${ }^{2}$ \\
\hline$N$ & 64 & 64 & \\
\hline Age at blood draw, years & 58 & 57 & Matched \\
\hline $\begin{array}{l}\text { Median time from serum } \\
\text { collection to diagnosis } \\
\text { (years, interdecile range) }\end{array}$ & - & $9.0(3.0-20.0)$ & - \\
\hline Height (cm) & 173.9 & 174.4 & 0.93 \\
\hline Weight (kg) & 80.2 & 77.0 & 0.069 \\
\hline BMI $\left(\mathrm{kg} / \mathbf{~ m}^{2}\right)$ & 26.5 & 25.3 & 0.025 \\
\hline History of diabetes $(\%)$ & 7.8 & 3.1 & 0.24 \\
\hline Cigarettes per day & 21.1 & 20.2 & 0.45 \\
\hline Years of cigarette smoking & 36.5 & 35.4 & 0.57 \\
\hline Physically active (\%) & 18.8 & 23.4 & 0.67 \\
\hline Serum retinol $(\mu \mathrm{g} / \mathrm{L})$ & 592.3 & 586.4 & 0.76 \\
\hline $\begin{array}{l}\text { Serum total cholesterol } \\
(\mathrm{mmol} / \mathrm{L})\end{array}$ & 6.2 & 6.2 & 0.70 \\
\hline Serum $\alpha$-tocopherol $(\mathrm{mg} / \mathrm{L})$ & 12.0 & 11.4 & 0.057 \\
\hline Serum $\beta$-carotene $(\mu \mathrm{g} / \mathrm{L})$ & 178.7 & 214.3 & 0.55 \\
\hline \multicolumn{4}{|l|}{ Dietary intake per day } \\
\hline Total energy (kcal) & 2776.9 & 2634.0 & 0.33 \\
\hline Fruit (g) & 114.0 & 135.0 & 0.25 \\
\hline Vegetables (g) & 121.2 & 106.2 & 0.21 \\
\hline Red meat (g) & 78.0 & 67.8 & 0.059 \\
\hline Coffee (g) & 558.6 & 631.6 & 0.21 \\
\hline Alcohol (ethanol, g) & 18.0 & 14.8 & 0.64 \\
\hline \multicolumn{4}{|l|}{ Supplement use } \\
\hline Vitamin A $(\%)$ & 9.4 & 7.8 & 1.00 \\
\hline Vitamin D (\%) & 6.3 & 7.8 & 1.00 \\
\hline Calcium (\%) & 10.9 & 12.5 & 1.00 \\
\hline
\end{tabular}

${ }^{1}$ Values are means unless otherwise indicated. All data were obtained at baseline.

${ }^{2}$ Wilcoxon rank test for continuous variables, or Fisher's exact test for categorical variables.

$(P=0.034)$, whereas urea cycle/arginine and proline, glycolysis/gluconeogenesis/pyruvate, monoacylglycerol, histidine, food component/plant, and diacylglycerol metabolites were related to risk of glioma after nine years $(0.003 \leq P<0.045$, Supplementary Table 4$)$. These pathway associations did not, however, reach the stringent Bonferroni significance threshold for correction of multiple comparisons [i.e., eight tests for super-pathways $(P=0.0063)$ and 70 tests for sub-pathways $(P=0.00071)]$.

\section{DISCUSSION}

Our study identified the amino acids 2-oxoarginine, cysteine and argininate, energy metabolite alphaketoglutarate, and secondary bile acid chenodeoxycholate, as well as some other compounds, as being lower in circulation of glioma cases years in advance of diagnosis compared to study-based controls. By contrast, we show several xanthine metabolites of caffeine to be related 
Table 2: Serum metabolites related to risk of overall glioma $(P<0.05)^{1}$

\begin{tabular}{|c|c|c|c|c|c|}
\hline Metabolite & Sub-pathway & $\begin{array}{l}\text { Odds } \\
\text { Ratio }\end{array}$ & $95 \% \mathrm{CI}$ & $\begin{array}{c}P \\
\text { value }\end{array}$ & $\begin{array}{l}P \text { for chemical } \\
\text { class }\end{array}$ \\
\hline $\begin{array}{l}\text { Amino acids and amino acid } \\
\text { derivatives }\end{array}$ & & & & & 0.14 \\
\hline Glutamate & Glutamate metabolism & 0.65 & $0.43,0.96$ & 0.0321 & \\
\hline N-Acetylleucine & $\begin{array}{l}\text { Leucine, isoleucine and valine } \\
\text { metabolism }\end{array}$ & 0.67 & $0.44,1.00$ & 0.0499 & \\
\hline Cysteine & $\begin{array}{l}\text { Methionine, cysteine, SAM and taurine } \\
\text { metabolism }\end{array}$ & 0.39 & $0.19,0.77$ & 0.0069 & \\
\hline Cysteine-S-sulfate & $\begin{array}{l}\text { Methionine, cysteine, SAM and taurine } \\
\text { metabolism }\end{array}$ & 0.62 & $0.40,0.96$ & 0.0323 & \\
\hline N-Acetyltyrosine & Phenylalanine and tyrosine metabolism & 0.57 & $0.36,0.88$ & 0.0109 & \\
\hline N-Acetylphenylalanine & Phenylalanine and tyrosine metabolism & 0.63 & $0.41,0.96$ & 0.0326 & \\
\hline Phenyllactate (PLA) & Phenylalanine and tyrosine metabolism & 0.67 & $0.46,0.97$ & 0.0350 & \\
\hline Tyrosine & Phenylalanine and tyrosine metabolism & 0.71 & $0.50,1.00$ & 0.0477 & \\
\hline N-Acetylkynurenine & Tryptophan metabolism & 0.65 & $0.43,0.98$ & 0.0420 & \\
\hline N-Acetyltryptophan & Tryptophan metabolism & 0.64 & $0.41,0.98$ & 0.0421 & \\
\hline Xanthurenate & Tryptophan metabolism & 0.67 & $0.45,0.99$ & 0.0453 & \\
\hline 2-Oxoarginine & $\begin{array}{l}\text { Urea cycle; arginine and proline } \\
\text { metabolism }\end{array}$ & 0.56 & $0.37,0.85$ & 0.0065 & \\
\hline Argininate & $\begin{array}{l}\text { Urea cycle; arginine and proline } \\
\text { metabolism }\end{array}$ & 0.60 & $0.42,0.88$ & 0.0083 & \\
\hline N-Acetylarginine & $\begin{array}{l}\text { Urea cycle; arginine and proline } \\
\text { metabolism }\end{array}$ & 0.69 & $0.48,0.98$ & 0.0407 & \\
\hline Carbohydrates & & & & & 0.36 \\
\hline Mannitol/sorbitol & $\begin{array}{l}\text { Fructose, mannose and galactose } \\
\text { metabolism }\end{array}$ & 0.63 & $0.41,0.97$ & 0.0374 & \\
\hline Pyruvate & $\begin{array}{l}\text { Glycolysis, gluconeogenesis, and } \\
\text { pyruvate metabolism }\end{array}$ & 0.65 & $0.43,0.97$ & 0.0343 & \\
\hline Cofactors and Vitamins & & & & & 0.23 \\
\hline $\begin{array}{l}\text { Trigonelline (N'- } \\
\text { methylnicotinate) }\end{array}$ & $\begin{array}{l}\text { Nicotinate and nicotinamide } \\
\text { metabolism }\end{array}$ & 1.72 & $1.10,2.69$ & 0.0182 & \\
\hline Alpha-tocopherol & Tocopherol metabolism & 0.65 & $0.44,0.96$ & 0.0305 & \\
\hline Energy & & & & & 0.25 \\
\hline Alpha-ketoglutarate & TCA cycle & 0.52 & $0.32,0.84$ & 0.0075 & \\
\hline Lipids & & & & & 0.36 \\
\hline Stearoylcarnitine (C18) & Fatty acid metabolism (Acyl carnitine) & 1.58 & $1.09,2.29$ & 0.0159 & \\
\hline Margaroylcarnitine & Fatty acid metabolism (Acyl carnitine) & 1.50 & $1.05,2.15$ & 0.0251 & \\
\hline Eicosenoylcarnitine (C20:1) & Fatty acid metabolism (Acyl carnitine) & 1.59 & $1.01,2.51$ & 0.0457 & \\
\hline $\begin{array}{l}\text { 1-Palmitoyl-2-linoleoyl-GPI } \\
(16: 0 / 18: 2)\end{array}$ & Phospholipid metabolism & 0.61 & $0.41,0.91$ & 0.0147 & \\
\hline Glycerophosphorylcholine (GPC) & Phospholipid metabolism & 1.76 & $1.00,3.10$ & 0.0484 & \\
\hline
\end{tabular}




\begin{tabular}{|c|c|c|c|c|c|}
\hline Metabolite & Sub-pathway & $\begin{array}{l}\text { Odds } \\
\text { Ratio }\end{array}$ & $95 \% \mathrm{CI}$ & $\begin{array}{c}P \\
\text { value }\end{array}$ & $\begin{array}{l}P \text { for chemical } \\
\text { class }\end{array}$ \\
\hline $\begin{array}{l}\text { 1-(1-Enyl-palmitoyl)-2-oleoyl- } \\
\text { GPC (P-16:0/18:1) }\end{array}$ & Plasmalogen & 1.47 & $1.01,2.15$ & 0.0449 & \\
\hline Chenodeoxycholate & Primary bile acid metabolism & 0.56 & $0.37,0.86$ & 0.0082 & \\
\hline Cholate & Primary bile acid metabolism & 0.6 & $0.39,0.91$ & 0.0162 & \\
\hline $3 \beta$-Hydroxy-5-cholenoic acid & Secondary bile acid metabolism & 0.67 & $0.45,0.98$ & 0.0393 & \\
\hline Glycocholenate sulfate & Secondary bile acid metabolism & 0.64 & $0.41,0.98$ & 0.0420 & \\
\hline $\begin{array}{l}\text { Sphingomyelin (d18:1/17:0, } \\
\text { d17:1/18:0, d19:1/16:0) }\end{array}$ & Sphingolipid metabolism & 1.67 & $1.07,2.61$ & 0.0228 & \\
\hline Nucleotides & & & & & 0.59 \\
\hline Cytidine & $\begin{array}{l}\text { Pyrimidine metabolism, cytidine } \\
\text { containing }\end{array}$ & 1.49 & $1.01,2.19$ & 0.0471 & \\
\hline Peptides & & & & & 0.64 \\
\hline Gamma-glutamyltyrosine & Gamma-glutamyl amino acid & 0.61 & $0.40,0.92$ & 0.0175 & \\
\hline Xenobiotics & & & & & 0.58 \\
\hline Propyl 4-hydroxybenzoate sulfate & Benzoate metabolism & 0.54 & $0.32,0.92$ & 0.0230 & \\
\hline $\begin{array}{l}\text { Methyl 4-hydroxybenzoate } \\
\text { sulfate }\end{array}$ & Benzoate metabolism & 0.67 & $0.46,0.97$ & 0.0320 & \\
\hline 3-Methyl catechol sulfate & Benzoate metabolism & 1.53 & $1.02,2.28$ & 0.0380 & \\
\hline Quinate & Food component/plant & 1.52 & $1.03,2.25$ & 0.0334 & \\
\hline 1-Methylurate & Xanthine metabolism & 1.58 & $1.08,2.30$ & 0.0171 & \\
\hline 1-Methylxanthine & Xanthine metabolism & 1.63 & $1.09,2.46$ & 0.0184 & \\
\hline Paraxanthine & Xanthine metabolism & 1.52 & $1.05,2.22$ & 0.0284 & \\
\hline Theobromine & Xanthine metabolism & 1.53 & $1.02,2.28$ & 0.0375 & \\
\hline $\begin{array}{l}\text { 5-Acetylamino-6-amino-3- } \\
\text { methyluracil }\end{array}$ & Xanthine metabolism & 1.55 & $1.02,2.35$ & 0.0379 & \\
\hline Theophylline & Xanthine metabolism & 1.50 & $1.02,2.22$ & 0.0412 & \\
\hline 7-Methylxanthine & Xanthine metabolism & 1.47 & $1.01,2.14$ & 0.0415 & \\
\hline
\end{tabular}

${ }^{1}$ Conditional logistic regression models were used to estimate odds ratio and their $95 \%$ confidence intervals (CIs), with only matching factors adjusted in the model. The odds ratio is for one-standard deviation increase in metabolite level. The table is sorted by chemical class, sub-pathway, and $P$ value. The analysis is based on 64 cases and 64 controls.

to higher risk. Ascorbate and aldarate metabolites are associated with high-grade glioma, while glycolysis/ gluconeogenesis/pyruvate, eicosanoid and glutamate metabolites appeared related to lower-grade disease.

A possible role for coffee consumption in the etiology of glioma has long been hypothesized, and a meta-analysis of four prospective and two retrospective studies showed no association [15]. Previous research has identified several coffee-related metabolites in circulation, including quinate, 1-methylurate, 1-methylxanthine, paraxanthine, theobromine, 5-acetylamino-6-amino3-methyluracil, theophylline, 7-methylxanthine, and trigonelline [16], with many of these compounds showing substantial positive associations with overall glioma risk in the present investigation. Whether these xanthine metabolites have a direct causal role in glioma, or are elevated years in advance of diagnosis because of increased coffee consumption in response to tumor-related neurologic changes or cancer-related fatigue, for example, will require additional clinical and prospective studies.

The arginine/proline metabolic pathway compounds 2-oxoarginine, a guanidino metabolite of arginine, and argininate, the conjugate base of arginine, were substantially lower in men years in advance - and 
Table 3: Serum metabolites related to risk of high-grade glioma $(P<0.05)^{1}$

\begin{tabular}{|c|c|c|c|c|c|}
\hline Metabolite & Sub-pathway & Odds Ratio & $95 \%$ CI & $P$ value & $\begin{array}{c}P \text { for chemical } \\
\text { class }\end{array}$ \\
\hline $\begin{array}{l}\text { Amino acids and amino } \\
\text { acid derivatives }\end{array}$ & & & & & 0.85 \\
\hline N-Acetylglutamate & Glutamate metabolism & 1.99 & $1.10,3.61$ & 0.0228 & \\
\hline $\begin{array}{l}\text { 2,3-Dihydroxy-2- } \\
\text { methylbutyrate }\end{array}$ & $\begin{array}{l}\text { Leucine, isoleucine and valine } \\
\text { metabolism }\end{array}$ & 2.05 & $1.09,3.85$ & 0.0258 & \\
\hline Cysteine & $\begin{array}{l}\text { Methionine, cysteine, SAM and } \\
\text { taurine metabolism }\end{array}$ & 0.44 & $0.20,0.98$ & 0.0437 & \\
\hline Carbohydrates & & & & & 0.48 \\
\hline Ribonate & Pentose metabolism & 2.53 & $1.02,6.25$ & 0.0445 & \\
\hline Cofactors and Vitamins & & & & & 0.07 \\
\hline Oxalate (ethanedioate) & $\begin{array}{l}\text { Ascorbate and aldarate } \\
\text { metabolism }\end{array}$ & 0.55 & $0.33,0.91$ & 0.0211 & \\
\hline Threonate & $\begin{array}{l}\text { Ascorbate and aldarate } \\
\text { metabolism }\end{array}$ & 0.57 & $0.34,0.95$ & 0.0300 & \\
\hline Gulonate & $\begin{array}{l}\text { Ascorbate and aldarate } \\
\text { metabolism }\end{array}$ & 1.99 & $1.04,3.81$ & 0.0387 & \\
\hline Energy & & & & & 0.49 \\
\hline Aconitate [cis or trans] & TCA cycle & 1.70 & $1.00,2.89$ & 0.0502 & \\
\hline Lipids & & & & & 0.97 \\
\hline $\begin{array}{l}\text { Oleoyl-oleoyl-glycerol } \\
(18: 1 / 18: 1)\end{array}$ & Diacylglycerol & 1.85 & $1.03,3.31$ & 0.0402 & \\
\hline Cholate & Primary bile acid metabolism & 0.54 & $0.31,0.93$ & 0.0273 & \\
\hline Glycocholenate sulfate & Secondary bile acid metabolism & 0.39 & $0.19,0.79$ & 0.0091 & \\
\hline $\begin{array}{l}3 \beta \text {-Hydroxy-5-cholenoic } \\
\text { acid }\end{array}$ & Secondary bile acid metabolism & 0.49 & $0.28,0.85$ & 0.0106 & \\
\hline $\begin{array}{l}\text { 5Alpha-pregnan-3beta, } \\
\text { 20beta-diol monosulfate }\end{array}$ & Steroid & 0.56 & $0.34,0.92$ & 0.0209 & \\
\hline Pregnenolone sulfate & Steroid & 0.53 & $0.30,0.94$ & 0.0293 & \\
\hline Nucleotides & & & & & 0.15 \\
\hline $\begin{array}{l}\text { 5-Methyluridine } \\
\text { (ribothymidine) }\end{array}$ & $\begin{array}{l}\text { Pyrimidine metabolism, uracil } \\
\text { containing }\end{array}$ & 2.25 & $1.12,4.52$ & 0.0226 & \\
\hline Xenobiotics & & & & & 0.63 \\
\hline $\begin{array}{l}\text { Tartronate } \\
\text { (hydroxymalonate) }\end{array}$ & Bacterial/fungal & 0.57 & $0.34,0.97$ & 0.0383 & \\
\hline $\begin{array}{l}\text { Methyl 4-hydroxybenzoate } \\
\text { sulfate }\end{array}$ & Benzoate metabolism & 0.47 & $0.26,0.83$ & 0.0097 & \\
\hline $\begin{array}{l}\text { Propyl 4-hydroxybenzoate } \\
\text { sulfate }\end{array}$ & Benzoate metabolism & 0.52 & $0.28,0.97$ & 0.0391 & \\
\hline
\end{tabular}

${ }^{1}$ Conditional logistic regression models were used to estimate odds ratio and their $95 \%$ confidence intervals (CIs), with only matching factors adjusted in the model. The odds ratio is for one-standard deviation increase in metabolite level. The table is sorted by chemical class, sub-pathway, and $p$ value. The grade is based on World Health Organization Grade of glioma, and Grade IV is defined as high-grade. The analysis is based on 41 cases and 41 controls. 
Table 4: Gene set analysis (GSA) for sub-pathways of serum metabolites and risk of glioma $(P<0.05)^{1}$

\begin{tabular}{lcc}
\hline Sub-pathway & No. of contributing metabolites & P value from GSA \\
\hline Overall glioma & 8 & 0.005 \\
Primary bile acid metabolism & 16 & 0.032 \\
Urea cycle; arginine and proline metabolism & 3 & 0.034 \\
Tocopherol metabolism & 2 & 0.045 \\
Fatty acid, amino & 5 & 0.048 \\
Glycolysis, gluconeogenesis, and pyruvate metabolism & & \\
High-grade glioma & 3 & 0.02 \\
Ascorbate and aldarate metabolism & & \\
Lower-grade glioma & 9 & 0.006 \\
Glutamate metabolism & 5 & 0.017 \\
Glycolysis, gluconeogenesis, and pyruvate metabolism & 2 & 0.03 \\
Eicosanoid & 6 & 0.04 \\
Alanine and aspartate metabolism & 5 & \\
\hline
\end{tabular}

${ }^{1} \mathrm{GSA}$, a standard pathway method, was used to examine whether the pre-defined sub-pathways were associated with glioma status. The grade is based on the World Health Organization Grade of glioma, and Grade IV is defined as high-grade, and Grade II-III is defined as lower-grade. The GSA sub-pathway analysis for overall glioma is based on 64 cases and 64 controls, for high-grade glioma is based on 41 cases and 41 controls, for lower-grade glioma is based on 19 cases and 19 controls.

especially nine or more years - of being diagnosed with glioma compared with non-cases. A recent plasma metabolomic analysis of 87 glioma patients found lower arginine concentrations in high-grade glioma compared to low-grade, suggesting greater arginine dependence of the former [17]. Earlier studies have indicated that arginine/proline metabolites are involved in tumorigenesis (including glioblastoma), exogenous arginine is required for tumor growth, and arginine deprivation leads to impairment of glioma cell motility, invasiveness, and adhesion [18-21].

A large proportion (i.e., 60-90\%) of low-grade gliomas harbor a heterozygous mutation $(\mathrm{R} 132 \mathrm{H})$ in the gene encoding the cytosolic isoform of isocitrate dehydrogenase (IDH1) [22]. Data from genome-wide association studies of glioma have identified single nucleotide polymorphisms (SNP) associated with altered risk of $I D H$-mutated glioma, including rs55705857 in 8q24.21, rs4295627 in CCDC26, and rs498872 in PHLDB1 [23, 24], and in a recent case-control study of 285 gliomas, 316 healthy controls, and 531 other types of cancers, the authors showed that SNP rs55705857 was strongly associated with altered risk of $I D H$-mutant glioma, but not with other cancers [23]. The wild-type IDH1 catalyzes the oxidative decarboxylation of isocitrate to generate alpha-ketoglutarate $(\alpha-K G)$, whereas the mutant enzyme is able to convert $\alpha-\mathrm{KG}$ into molecules of 2-HG, which is an "oncometabolite" that may mediate several tumorigenic events [25-27]. In the present study, we observed increased pre-diagnostic serum 2-HG and decreased $\alpha-K G$ in glioma cases. We could not, however, evaluate IDHI mutation status and its correlation with serum 2-HG, although previous studies indicated no correlation between serum 2-HG and IDH1/2 status or tumor size $[17,28]$. On the other hand, it is unlikely that the serum $2-\mathrm{HG}$ and $\alpha-\mathrm{KG}$ reflect early cellular changes in transformed astrocytes or emerging gliomas, but rather etiologic biomarkers that must be considered and further evaluated in other studies. It is of note that we observed that another TCA cycle metabolite, aconitate (related to cis-aconitate), was elevated in high-grade cases $(\mathrm{OR}=1.7$, $P=0.05$ ).

Being a highly metabolically active organ, the brain generates substantial reactive oxygen species (ROS) and is slower to neutralize these free radicals compared to other tissues [29], possibly leading to DNA damage, genomic instability and tumor development. We found several antioxidant pathway metabolites inversely associated with risk that may be indicative of serum antioxidant depletion resulting from increased tumor ROS. For example, both cysteine and cysteine-S-sulfate were lower in cases, and this might be associated with increased cysteine uptake, and modulating of redox status, in the central nervous system. The conditionally essential amino acid 
cysteine is a rate-limiting precursor for the antioxidant glutathione, one of the most abundant antioxidants in the central nervous system $[30,31]$. Whereas cysteine is an extracellular antioxidant, glutathione acts intracellularly and may play a role in glioma cell survival under redox stress and hypoxic conditions [30-32]. Consistent with this is a metabolomic study of patient-derived glioma tissue that found cysteine catabolism and cysteine sulfinic acid accumulation in the high-grade glioblastoma cases [33]. Higher circulating cysteine has also been related to lower risks of several other cancers including colon [34], esophagus, and stomach [35].

Also relevant to ROS and glioma risk is the inverse association we observed for alpha-tocopherol, the most biologically active form of vitamin $\mathrm{E}$ and a potent inhibitor of lipid peroxidation [36]. Two previous studies had similar findings for glioma and glioblastoma [37, 38], while a recent report showed positive associations for several antioxidants including alpha-tocopherol [39]. The latter finding was, however, restricted to risk 10-22 years after blood collection [39]. By contrast, and also relevant to the metabolite-ROS-glioma associations, we showed two of three compounds in the ascorbate/aldarate pathway were inversely associated with high-grade disease.

5Alpha-pregnan-3beta, 20beta-diol monosulfate and pregnenolone sulfate were reduced in high-grade glioma cases. The latter is considered a neurosteroid that can be synthesized in the central nervous system, is present in higher concentrations in brain tissue than in plasma [40, $41]$, and is a precursor of some neurosteroids characterized as having neuroprotective effects $[42,43]$. Experimental data also indicate that pregnenolone can regulate glioma cell death through extrinsic and intrinsic apoptotic pathways in a caspase-dependent manner [44].

Altered energy metabolism has been considered one of the hallmarks of cancer [45]. Glycolysis, as a highly conserved metabolic process, is essential for energy production in normal mammalian cells, and impairment of glycolysis has been depicted as a feature of cancer metabolism; i.e., the Warburg effect [46-48]. Impairment of glycolysis in glioma has been found in the present study (especially in low-grade tumors), as well as in previous studies (distinguishing low- and high-grade tumors) $[10,17]$. One of the previous studies [10] that identified a total of 308 known biochemicals and used fresh-frozen tumor tissue found alterations in glucose metabolism as a function of tumor grade, especially distinguishing grade IV tumors from grade II (33 grade IV tumors and 18 grade II tumors). Another study [17] using serum that detected a total of 224 known metabolites from 25 key metabolic pathways reported that the carbohydrate pathway (e.g. glycolysis or gluconeogenesis) was ranked 6th of 18 metabolic pathways that significantly differed between high- and low-grade glioma. They have defined low-grade glioma $(\mathrm{N}=42)$ as grade I and II, and high-grade $(\mathrm{N}=45)$ glioma as grade III and IV. Based on differences in study designs, including biospecimen type (serum vs. tissue), reference groups (healthly controls in the present study vs. low-grade glioma cases in previous clinical studies), number of identified metabolites (730 known metabolites in the present study vs. 200-300 metabolites in the previous studies), and definition of low- and high-grade glioma (grade II and III as low-grade and grade IV as high-grade in the present study $v s$. grade I/ II as low-grade and grade III/IV as high grade), a direct comparison across the studies is not facile and involves imprecision. Our findings suggest that impairment of the glycolysis pathway may be an early event during glioma development, likely to support cell proliferation and tumor anabolic activity. Of note, impairment of glycolysis has been shown in earlier studies to be associated with activated oncogenes (such as $R A S$, or $M Y C$ ) and mutant tumor suppressors (such as TP53) $[45,49,50]$ and such mutations have been reported to occur more frequently in low-grade rather than high-grade gliomas [51-53].

Notable strengths of our investigation include assaying of overnight fasting serum samples that were obtained up to two decades prior to the diagnosis of glioma. Cases were ascertained from census-based population registers with high accuracy. Untargeted metabolomic profiling was able to identify several hundred metabolites using a high-quality platform with careful quality control and laboratory blinding to case-control status. Study limitations include the homogenous nature of the Finnish male smoker population which impacts the generalizability of our findings to other populations. Also, serum metabolites were only measured at one blood sampling time-point, whereas additional timepoints would have provided a more robust reflection of one's usual or average profile. We are unable to access tumor tissue for glioma genotyping, such as for IDH mutation, thus we could not classify gliomas based on this factor. Our study sample size was relatively small for an agnostic investigation, albeit glioma is a relatively rare malignancy and all available cases were studied. Although none of our findings exceeded statistically significant thresholds for multiple comparisons, a large number of the metabolites were highly correlated with one another (e.g., fatty acids), which makes the Bonferroni threshold particularly stringent in that the tests were not completely independent. Nonetheless, our findings should be considered preliminary and hypothesis-generating, even with respect to top signals that were consistent with data from previous studies.

In conclusion, the present study finds a serum metabolomic profile of glioma up to 20 years prior to clinical diagnosis that is characterized by altered molecular signals in arginine/proline, antioxidant, and coffee-related metabolites. Ascorbate/aldarate and steroid hormone metabolites were found to be associated with high-grade glioma. The observed profiles provide evidence regarding the molecular basis relevant to etiologic or sub-clinical 
biomarkers for glioma. Further prospective metabolomic studies are needed to re-examine the findings in larger and more diverse populations.

\section{MATERIALS AND METHODS}

\section{Study population}

The ATBC Study was a $2 \times 2$ factorial, randomized, double-blind, placebo-controlled primary prevention trial originally conducted to examine whether $\alpha$-tocopherol and $\beta$-carotene supplementation could reduce incidence of cancer [54]. Details of the study have been described [54]. Briefly, the trial enrolled Caucasian male smokers $(n=29,133)$, aged 50-69 years from 1985 to 1988 in southwest Finland. The participants were randomly assigned to receive one of four supplements: $\alpha$-tocopherol ( $50 \mathrm{mg} /$ day), $\beta$-carotene $(20 \mathrm{mg} /$ day), both or placebo for 5-8 years (median $=6.1$ ) through the end of the trial (April 30, 1993). Pre-supplementation fasting blood samples from all participants (years prior to cancer diagnoses) were collected during the baseline visit, and stored at $-70{ }^{\circ} \mathrm{C}$ until assessment. At enrollment, self-reported questionnaires were completed with information regarding general health, behavioral and lifestyle factors, and height and weight were measured. Participants were followed from date of enrollment, to date of glioma diagnosis (Finnish Cancer Registry), date of death (Finnish Register of Causes of Death), or censor date (December 31, 2012), whichever occurred first.

All participants provided written informed consent at enrollment. The ATBC Study was approved by institutional review boards at the U.S. National Cancer Institute and the Finnish National Institute for Health and Welfare.

\section{Case ascertainment and control selection}

A total of 64 glioma cases (ICD-9 191, ICD-O morphology code 9380-9481), including 41 high-grade, 19 lower-grade and 4 unknown grade, ascertained during the follow-up period are included in the present analysis. Using incidence-density sampling without replacement, we randomly selected 64 matched controls based on age ( \pm 1 year) and date of blood collection ( \pm 30 days).

\section{Metabolite assessment}

Ultrahigh performance liquid chromatograph/ tandem mass spectrometry (LC-MS/MS), a high resolution accurate mass (HRAM) platform at Metabolon Inc., was used to determine serum metabolomic profiles as previously described $[55,56]$. To summarize, extraction of samples was processed using an automated liquid handling robot (Hamilton LabStar, Hamilton Robotics, Inc., Reno, $\mathrm{NV}$ ), and $450 \mu \mathrm{l}$ of methanol was added to $100 \mu \mathrm{l}$ of sample to precipitate proteins. To confirm extraction efficiency, four recovery standards were added to the methanol, including DL-2-fluorophenylglycine, tridecanoic acid, d6cholesterol and 4-chlorophenylalanine. Four aliquots from each sample were obtained and dried. For the negative ion analysis, two aliquots of each serum sample were reconstituted in $50 \mu 1$ of $6.5 \mathrm{mM}$ ammonium bicarbonate in water with a $\mathrm{pH}$ of 8 . For the positive ion analysis, another two aliquots of each serum sample were reconstituted using $50 \mu \mathrm{l} 0.1 \%$ formic acid in water with a $\mathrm{pH}$ of 3.5 . The procedures further included raw data extraction, peakidentification and quality control (QC) inclusion in each assay. The assays were run in four batches, each batch contained 16 case-control pairs and two QC samples. We identified a total of 1,064 metabolites, of which 311 metabolites were unknown, and 753 were known molecules. We excluded 23 metabolites that were missing (i.e. below the limit of detection) in $>110$ study individuals (86\%), leaving a total of 730 identified compounds in the final analysis. Metabolites were categorized into one of eight mutually exclusive chemical classes: amino acids and amino acid derivatives (subsequently refer to as "amino acids"), carbohydrates, cofactors and vitamins, energy metabolites, lipids, nucleotides, peptides or xenobiotics. CVs and ICCs were used to assess the data reliability. The $\mathrm{CV}$ is defined as the square root of the within-subject variance divided by the mean value. The lower the $\mathrm{CV}$, the better the assay repeatability. The ICC is defined as the between-individual variance divided by the total variance. The range of ICC values are $0-1$, and close to 0 suggests little to null reproducibility, whereas close to 1 indicates good reproducibility. Rosner has proposed the classification of ICCs as poor $(<0.4)$, fair-to-good (0.4$0.75)$, and excellent $(\geq 0.75)$ [57].

\section{Statistical analyses}

We used either Wilcoxon rank sum (for continuous variables) or Fisher's exact test (for categorical variables) to compare the demographic characteristics of cases and controls. To standardize the batch variability, we normalized each metabolite within a given batch by dividing by the batch mean of all non-missing values. Metabolites with missing values were imputed to the minimum of the observed values. Metabolite levels were then log-transformed and normalized to have mean $=0$ and variance $=1$. We modeled the association between glioma and each normalized log-transformed metabolite level by conditional logistic regression and report the ORs for a 1-standard deviation (SD) increase and their $95 \%$ CIs, with only matching factors adjusted in the final model. The threshold for statistical significance was defined by Bonferroni correction in the primary analysis with 730 tests $(P=0.000068)$. We next performed principle component analysis [58] and repeated the conditional logistic regression for each of 
the top 10 principal components. We then used GSA, a standard pathway method, to examine whether any of the pre-defined sub or super-pathways were associated with glioma status [59].

Sensitivity analyses were performed, including restriction to high-grade case-control pairs, and stratification by age at enrollment $(<56 v s . \geq 56$ years, median age as cutoff point), time to diagnosis $(<9 v s . \geq 9$ years, median time as cutoff point), and caffeine intake ( $<560 v s . \geq 560$ gram, median as cutoff point). Additional analyses adjusted (separately) for BMI (continuous), height (continuous), history of diabetes (yes or no), physical activity (no activity vs. at least light activity), and number of daily cigarettes, red meat consumption, and alcohol consumption (all continuous).

The R statistical language version 3.2.3 (Vienna, Austria) was used for GSA analysis, and SAS software version 9.3 (SAS Institute, Cary, NC) was used for other analyses. All presented $P$-values are two-sided.

\section{CONFLICTS OF INTEREST}

EDK is employed by Metabolon, Inc.

JH, SJW, CMK, JNS and DA declare no conflicts of interest.

\section{FUNDING}

The ATBC Study is supported by the Intramural Research Program of the U.S. National Cancer Institute, National Institutes of Health, and by U.S. Public Health Service contract HHSN261201500005C from the National Cancer Institute, Department of Health and Human Services.

\section{REFERENCES}

1. Ostrom QT, Bauchet L, Davis FG, Deltour I, Fisher JL, Langer CE, Pekmezci M, Schwartzbaum JA, Turner MC, Walsh KM, Wrensch MR, Barnholtz-Sloan JS. The epidemiology of glioma in adults: a "state of the science" review. Neuro Oncol. 2014; 16:896-913.

2. Bondy ML, Scheurer ME, Malmer B, Barnholtz-Sloan JS, Davis FG, Il'yasova D, Kruchko C, McCarthy BJ, Rajaraman P, Schwartzbaum JA, Sadetzki S, Schlehofer B, Tihan T, et al. Brain tumor epidemiology: consensus from the Brain Tumor Epidemiology Consortium. Cancer. 2008; 113:1953-1968.

3. Ohgaki H. Epidemiology of brain tumors. Methods Mol Biol. 2009; 472:323-342.

4. Omuro A, DeAngelis LM. Glioblastoma and other malignant gliomas: a clinical review. JAMA. 2013; 310:1842-1850.

5. Wigertz A, Lonn S, Schwartzbaum J, Hall P, Auvinen A, Christensen HC, Johansen C, Klaeboe L, Salminen T,
Schoemaker MJ, Swerdlow AJ, Tynes T, Feychting M. Allergic conditions and brain tumor risk. Am J Epidemiol. 2007; 166:941-950.

6. Lachance DH, Yang P, Johnson DR, Decker PA, Kollmeyer TM, McCoy LS, Rice T, Xiao Y, Ali-Osman F, Wang F, Stoddard SM, Sprau DJ, Kosel ML, et al. Associations of high-grade glioma with glioma risk alleles and histories of allergy and smoking. Am J Epidemiol. 2011; 174:574-581.

7. Chen C, Xu T, Chen J, Zhou J, Yan Y, Lu Y, Wu S. Allergy and risk of glioma: a meta-analysis. Eur J Neurol. 2011; 18:387-395.

8. Brennan CW, Verhaak RG, McKenna A, Campos B, Noushmehr H, Salama SR, Zheng S, Chakravarty D, Sanborn JZ, Berman SH, Beroukhim R, Bernard B, Wu CJ, et al. The somatic genomic landscape of glioblastoma. Cell. 2013; 155:462-477.

9. Frattini V, Trifonov V, Chan JM, Castano A, Lia M, Abate F, Keir ST, Ji AX, Zoppoli P, Niola F, Danussi C, Dolgalev I, Porrati $\mathrm{P}$, et al. The integrated landscape of driver genomic alterations in glioblastoma. Nat Genet. 2013; 45:1141-1149.

10. Chinnaiyan P, Kensicki E, Bloom G, Prabhu A, Sarcar B, Kahali S, Eschrich S, Qu X, Forsyth P, Gillies R. The metabolomic signature of malignant glioma reflects accelerated anabolic metabolism. Cancer Res. 2012; 72:5878-5888.

11. Nicholson JK, Lindon JC. Systems biology: metabonomics. Nature. 2008; 455:1054-1056.

12. O'Connell TM. Recent advances in metabolomics in oncology. Bioanalysis. 2012; 4:431-451.

13. Rousseau A, Mokhtari K, Duyckaerts C. The 2007 WHO classification of tumors of the central nervous system - what has changed? Curr Opin Neurol. 2008; 21:720-727.

14. Eckel-Passow JE, Lachance DH, Molinaro AM, Walsh KM, Decker PA, Sicotte H, Pekmezci M, Rice T, Kosel ML, Smirnov IV, Sarkar G, Caron AA, Kollmeyer TM, et al. Glioma groups based on 1p/19q, IDH, and TERT promoter mutations in tumors. N Engl J Med. 2015; 372:2499-2508.

15. Malerba S, Galeone C, Pelucchi C, Turati F, Hashibe M, La Vecchia C, Tavani A. A meta-analysis of coffee and tea consumption and the risk of glioma in adults. Cancer Causes Control. 2013; 24:267-276.

16. Guertin KA, Loftfield E, Boca SM, Sampson JN, Moore SC, Xiao Q, Huang WY, Xiong X, Freedman ND, Cross AJ, Sinha R. Serum biomarkers of habitual coffee consumption may provide insight into the mechanism underlying the association between coffee consumption and colorectal cancer. Am J Clin Nutr. 2015; 101:1000-1011.

17. Zhao H, Heimberger AB, Lu Z, Wu X, Hodges TR, Song $\mathrm{R}$, Shen J. Metabolomics profiling in plasma samples from glioma patients correlates with tumor phenotypes. Oncotarget. 2016; 7:20486-20495. https://doi.org/10.18632/ oncotarget. 7974 . 
18. Allen MD, Luong P, Hudson C, Leyton J, Delage B, Ghazaly E, Cutts R, Yuan M, Syed N, Lo Nigro C, Lattanzio L, Chmielewska-Kassassir M, Tomlinson I, et al. Prognostic and therapeutic impact of argininosuccinate synthetase 1 control in bladder cancer as monitored longitudinally by PET imaging. Cancer Res. 2014; 74:896-907.

19. Delage B, Fennell DA, Nicholson L, McNeish I, Lemoine NR, Crook T, Szlosarek PW. Arginine deprivation and argininosuccinate synthetase expression in the treatment of cancer. Int J Cancer. 2010; 126:2762-2772.

20. Patil MD, Bhaumik J, Babykutty S, Banerjee UC, Fukumura D. Arginine dependence of tumor cells: targeting a chink in cancer's armor. Oncogene. 2016; 35:4957-4972.

21. Pavlyk I, Rzhepetskyy Y, Jagielski AK, Drozak J, Wasik A, Pereverzieva G, Olchowik M, Kunz-Schugart LA, Stasyk $\mathrm{O}$, Redowicz MJ. Arginine deprivation affects glioblastoma cell adhesion, invasiveness and actin cytoskeleton organization by impairment of beta-actin arginylation. Amino Acids. 2015; 47:199-212.

22. Balss J, Meyer J, Mueller W, Korshunov A, Hartmann C, von Deimling A. Analysis of the IDH1 codon 132 mutation in brain tumors. Acta Neuropathol. 2008; 116:597-602.

23. Oktay Y, Ulgen E, Can O, Akyerli CB, Yuksel S, Erdemgil Y, Durasi IM, Henegariu OI, Nanni EP, Selevsek N, Grossmann J, Erson-Omay EZ, Bai H, et al. IDH-mutant glioma specific association of rs55705857 located at 8q24.21 involves MYC deregulation. Sci Rep. 2016; $6: 27569$.

24. Di Stefano AL, Enciso-Mora V, Marie Y, Desestret V, Labussiere M, Boisselier B, Mokhtari K, Idbaih A, HoangXuan K, Delattre JY, Houlston RS, Sanson M. Association between glioma susceptibility loci and tumour pathology defines specific molecular etiologies. Neuro Oncol. 2013; 15:542-547.

25. Choi C, Ganji SK, DeBerardinis RJ, Hatanpaa KJ, Rakheja D, Kovacs Z, Yang XL, Mashimo T, Raisanen JM, MarinValencia I, Pascual JM, Madden CJ, Mickey BE, et al. 2-hydroxyglutarate detection by magnetic resonance spectroscopy in IDH-mutated patients with gliomas. Nat Med. 2012; 18:624-629.

26. Cairns RA, Mak TW. Oncogenic isocitrate dehydrogenase mutations: mechanisms, models, and clinical opportunities. Cancer Discov. 2013; 3:730-741.

27. Nagashima H, Tanaka K, Sasayama T, Irino Y, Sato N, Takeuchi Y, Kyotani K, Mukasa A, Mizukawa K, Sakata J, Yamamoto Y, Hosoda K, Itoh T, et al. Diagnostic value of glutamate with 2-hydroxyglutarate in magnetic resonance spectroscopy for IDH1 mutant glioma. Neuro Oncol. 2016; 18:1559-1568.

28. Capper D, Simon M, Langhans CD, Okun JG, Tonn JC, Weller M, von Deimling A, Hartmann C, German Glioma N. 2-Hydroxyglutarate concentration in serum from patients with gliomas does not correlate with IDH1/2 mutation status or tumor size. Int J Cancer. 2012; 131:766-768.
29. Gadoth N, Göbel HH. Oxidative stress and free radical damage in neurology. New York: Humana Press. 2011.

30. Chung WJ, Lyons SA, Nelson GM, Hamza H, Gladson CL, Gillespie GY, Sontheimer H. Inhibition of cystine uptake disrupts the growth of primary brain tumors. J Neurosci. 2005; 25:7101-7110.

31. Ogunrinu TA, Sontheimer H. Hypoxia increases the dependence of glioma cells on glutathione. J Biol Chem. 2010; 285:37716-37724.

32. Celli A, Que FG, Gores GJ, LaRusso NF. Glutathione depletion is associated with decreased Bcl-2 expression and increased apoptosis in cholangiocytes. Am J Physiol. 1998; 275:G749-757.

33. Prabhu A, Sarcar B, Kahali S, Yuan Z, Johnson JJ, Adam KP, Kensicki E, Chinnaiyan P. Cysteine catabolism: a novel metabolic pathway contributing to glioblastoma growth. Cancer Res. 2014; 74:787-796.

34. Miller JW, Beresford SA, Neuhouser ML, Cheng TY, Song $\mathrm{X}$, Brown EC, Zheng Y, Rodriguez B, Green R, Ulrich CM. Homocysteine, cysteine, and risk of incident colorectal cancer in the Women's Health Initiative observational cohort. Am J Clin Nutr. 2013; 97:827-834.

35. Murphy G, Fan JH, Mark SD, Dawsey SM, Selhub J, Wang J, Taylor PR, Qiao YL, Abnet CC. Prospective study of serum cysteine levels and oesophageal and gastric cancers in China. Gut. 2011; 60:618-623.

36. de Oliveira BF, Costa DC, Nogueira-Machado JA, Chaves MM. beta-Carotene, alpha-tocopherol and ascorbic acid: differential profile of antioxidant, inflammatory status and regulation of gene expression in human mononuclear cells of diabetic donors. Diabetes Metab Res Rev. 2013; 29:636-645.

37. Schwartzbaum JA, Cornwell DG. Oxidant stress and glioblastoma multiforme risk: serum antioxidants, gammaglutamyl transpeptidase, and ferritin. Nutr Cancer. 2000; 38:40-49.

38. Schwartzbaum JA, Fisher JL, Goodman J, Octaviano D, Cornwell DG. Hypotheses concerning roles of dietary energy, cured meat, and serum tocopherols in adult glioma development. Neuroepidemiology. 1999; 18:156-166.

39. Bjorkblom B, Wibom C, Jonsson P, Moren L, Andersson U, Johannesen TB, Langseth $H$, Antti H, Melin B. Metabolomic screening of pre-diagnostic serum samples identifies association between alpha- and gammatocopherols and glioblastoma risk. Oncotarget. 2016; 7:37043-37053. https://doi.org/10.18632/oncotarget.9242.

40. Dubrovsky BO. Steroids, neuroactive steroids and neurosteroids in psychopathology. Prog Neuropsychopharmacol Biol Psychiatry. 2005; 29:169-192.

41. Mellon SH, Griffin LD. Neurosteroids: biochemistry and clinical significance. Trends Endocrinol Metab. 2002; 13:35-43.

42. Lacapere JJ, Papadopoulos V. Peripheral-type benzodiazepine receptor: structure and function of a 
cholesterol-binding protein in steroid and bile acid biosynthesis. Steroids. 2003; 68:569-585.

43. Borowicz KK, Piskorska B, Banach M, Czuczwar SJ. Neuroprotective actions of neurosteroids. Front Endocrinol (Lausanne). 2011; 2:50.

44. Xiao X, Chen L, Ouyang Y, Zhu W, Qiu P, Su X, Dou Y, Tang L, Yan M, Zhang H, Yang X, Xu D, Yan G. Pregnenolone, a cholesterol metabolite, induces glioma cell apoptosis via activating extrinsic and intrinsic apoptotic pathways. Oncol Lett. 2014; 8:645-650.

45. Hanahan D, Weinberg RA. Hallmarks of cancer: the next generation. Cell. 2011; 144:646-674.

46. Mikawa T, ME LL, Takaori-Kondo A, Inagaki N, Yokode M, Kondoh H. Dysregulated glycolysis as an oncogenic event. Cell Mol Life Sci. 2015; 72:1881-1892.

47. Koppenol WH, Bounds PL, Dang CV. Otto Warburg's contributions to current concepts of cancer metabolism. Nat Rev Cancer. 2011; 11:325-337.

48. Warburg O. On respiratory impairment in cancer cells. Science. 1956; 124:269-270.

49. DeBerardinis RJ, Lum JJ, Hatzivassiliou G, Thompson CB. The biology of cancer: metabolic reprogramming fuels cell growth and proliferation. Cell Metab. 2008; 7:11-20.

50. Jones RG, Thompson CB. Tumor suppressors and cell metabolism: a recipe for cancer growth. Genes Dev. 2009; 23:537-548

51. Cancer Genome Atlas Research Network; Brat DJ, Verhaak RG, Aldape KD, Yung WK, Salama SR, Cooper LA, Rheinbay E, Miller CR, Vitucci M, Morozova O, Robertson AG, Noushmehr $\mathrm{H}$, et al. Comprehensive, integrative genomic analysis of diffuse lower-grade gliomas. N Engl J Med. 2015; 372:2481-2498.

52. Chan AK, Mao Y, Ng HK. TP53 and histone H3.3 mutations in triple-negative lower-grade gliomas. N Engl J Med. 2016; 375:2206-2208.
53. Dubbink HJ, Atmodimedjo PN, Kros JM, French PJ, Sanson M, Idbaih A, Wesseling P, Enting R, Spliet W, Tijssen C, Dinjens WN, Gorlia T, van den Bent MJ. Molecular classification of anaplastic oligodendroglioma using next-generation sequencing: a report of the prospective randomized EORTC Brain Tumor Group 26951 phase III trial. Neuro Oncol. 2016; 18:388-400.

54. The ATBC Cancer Prevention Study Group. The alphatocopherol, beta-carotene lung cancer prevention study: design, methods, participant characteristics, and compliance. Ann Epidemiol. 1994; 4:1-10.

55. Evans AM, DeHaven CD, Barrett T, Mitchell M, Milgram E. Integrated, nontargeted ultrahigh performance liquid chromatography/electrospray ionization tandem mass spectrometry platform for the identification and relative quantification of the small-molecule complement of biological systems. Anal Chem. 2009; 81:6656-6667.

56. Evans AM, Bridgewater BB, Liu Q, Mitchell MW, Robinson RJ, Dai H, Stewart SJ, DeHaven CD, Miller L. High resolution mass spectrometry improves data quantity and quality as compared to unit mass resolution mass spectrometry in high-throughput profiling metabolomics. Metabolomics. 2014; 4:132. https://doi. org/10.4172/2153-0769.1000132.

57. Rosner BA. Fundamentals of Biostatistics (Rosner, Fundamentals of Biostatics). Duxbury Press. 2000. Multisample inference:pp. 511-576.

58. Jolliffe I. Principal component analysis. In: Encyclopedia of Statistics in Behavioral Science Chichester, UK: Wiley. 2005.

59. Subramanian A, Tamayo P, Mootha VK, Mukherjee S, Ebert BL, Gillette MA, Paulovich A, Pomeroy SL, Golub TR, Lander ES, Mesirov JP. Gene set enrichment analysis: a knowledge-based approach for interpreting genomewide expression profiles. Proc Natl Acad Sci U S A. 2005; 102:15545-15550. 